\title{
Intracellular Calcium Network Activity in the Hippocampus CA3 Region in Rat Postnatal Development
}

\author{
DOI: 10.17691/stm2016.8.4.21
}

Received March 15, 2016

Y.I. Mitaeva, PhD, Junior Researcher, Department of Neurotechnology, Institute of Biology and Biomedicine';

A.M. Mozherov, PhD Student, Junior Researcher, Department of Neurotechnology, Institute of Biology and Biomedicine';

I.A. Kastalskiy, Researcher, Laboratory for Development of Intellectual Biomechatronic Technology, Centre for Biotechnology Development, Institute of Biology and Biomedicine";

T.A. Mishchenko, PhD, Senior Researcher, Molecular and Cell Technologies Department, Central Research Laboratory²; Senior Researcher, Laboratory for Neuroprotection Methods Development, Institute of Biology and Biomedicine ${ }^{1 ;}$; Research Fellow, Laboratory of Laser Chemestry ${ }^{3}$;

I.V. Mukhina, DSc, Professor, Head of the Central Research Laboratory; Head of the Department of Normal Physiology named after N.Y. Belenkov2; Professor, Department of Neurotechnology, Institute of Biology and Biomedicine; Head of the Center of Translational Technology ${ }^{1}$

${ }^{1}$ Lobachevsky State University of Nizhni Novgorod, 23 Prospect Gagarina, Nizhny Novgorod, 603950,

Russian Federation;

${ }^{2}$ Nizhny Novgorod State Medical Academy, 10/1 Minin and Pozharsky Square, Nizhny Novgorod, 603005,

Russian Federation;

${ }^{3}$ Institute of Photon Technologies, Federal Scientific Research Center "Crystallography and Photonics" of the Russian Academy of Sciences, 2 Pionerskaya St., Moscow, Troitsk, 142190, Russian Federation

Hippocampus - the structure of the central nervous system, which is involved in the mechanisms of memory consolidation. The hippocampus has a certain topology distribution of cellular elements, which provides the many cellular networks. One of them is the network of neurons in the CA3 field. In this article discusses the features of the $\mathrm{Ca}^{2+}$ signaling system of cells of CA3 field of rat hippocampus of early (P5-8, P14-16) and late (P21-25) postnatal development in different physiological conditions: spontaneous activity, in violation of the excitation in the neural network by adding tetrodotoxin $\left(\mathrm{Ca}^{2+}\right.$ signaling), as well as the effects of excitatory neurotransmitters (ATP, L-glutamate). This work extends the concepts of $\mathrm{Ca}^{2+}$ signaling in rat hippocampus cells of early and late stages of postnatal ontogenesis. The study showed that changes in $\mathrm{Ca}^{2+}$ activity in the cells $\mathrm{CA} 3$ field of rat hippocampal taking place during the neonatal period of postnatal ontogenesis directly related to the functioning of neural networks and the metabolic state of the cells.

Key words: neuronal network; hippocampus; CA3 cells; astrocytes; $\mathrm{Ca}^{2+}$ imaging; postnatal development.

Introduction. Meaning of calcium signaling system in the brain is very large, because it is directly involved in the regulation of fundamental processes of neural integration, regulates various localized functional responses, and maintains the set of intracellular signaling pathways. Calcium signaling is the subject of many scientific research areas related to the study of the role of neurons and astrocytes in the functioning of the central nervous system (CNS) in health and disease [1-7]. Metabolism is impossible at millimolar levels of intracellular $\mathrm{Ca}^{2+}$, so all living cells retain the $\mathrm{Ca}^{2+}$ concentration at the low nanomolar level, thus creating a difference in gradients between cellular compartments and intercellular space $[8,9]$. Increase of intracellular $\mathrm{Ca}^{2+}$ concentration in the cell is a signaling process that triggers many biochemical reactions. $\mathrm{Ca}^{2+}$ activity of cells is the ability to quickly modify the intracellular concentration of $\mathrm{Ca}^{2+}$ in the form of oscillations. Spontaneous $\mathrm{Ca}^{2+}$ activity in the cells formed during the activation of ionotropic and metabotropic receptors, channels, regulates by the transporter proteins and probably depends on the stage of ontogenesis $[3,4]$.

Hippocampus - the structure of the central nervous system, which is involved in the mechanisms of emotion and memory consolidation. The hippocampus has a certain topology distribution of cellular elements, which provides work of many cellular networks [10-12]. One of these is the network of neurons in the CA3 field. This network receives inputs from cells of the entorhinal cortex and the dentate gyrus, moreover CA3 pyramidal neurons form the connection between themselves and interneurons, forming a closed network that operates in conditions of acute slice and generates spontaneous $\mathrm{Ca}^{2+}$ activity $[4,11,13,14]$. Therefore, to estimate the age dependence of $\mathrm{Ca}^{2+}$ activity in the cells were investigated $\mathrm{Ca}^{2+}$ oscillations in neuronal and glial networks and the interactions between them.

For contacts: Artem M. Mozherov, e-mail: artemmozherov@gmail.com 
In this study, we investigated changes in the characteristics of $\mathrm{Ca}^{2+}$ oscillations of cells of rat hippocampal CA3 field of early (P5-8, P14-16) and late (P21-25) postnatal development. Besides in the study was valued role of network activity in the formation of spontaneous $\mathrm{Ca}^{2+}$ oscillations of cells of rat hippocampal CA3 field in early and late stages of postnatal development.

\section{Materials and Methods}

Slice preparations. Experiments were performed on acute hippocampal slices prepared from the brains of male Wistar rats early (P5-8, P14-16) and late (P2125) stages of postnatal development. Male Wistar rats killed by cervical vertebra dislocation, according to the protocols approved by the National Ministry of Public Health for the care and use of laboratory animals and by the Bioethics Committee of the Nizhny Novgorod State Medical Academy. The work was performed in accordance with ethical principles established by European Convention for the Protection of Vertebrata used for Experimental and other Scientific Purposes (the Convention was passed in Strasburg, March 18, 1986, adopted in Strasburg, June 15, 2006). The brain was mounted on a vibratome (Microm HM 650V, Germany) and submerged in ice-cold Ringer solution that contained (in mM) $87 \mathrm{NaCl}, 2.5 \mathrm{KCl}, 26.2 \mathrm{NaHCO}_{3}, 1.24 \mathrm{NH}_{2} \mathrm{PO}_{4}$, $0.5 \mathrm{CaCl}_{2}, 8.48 \mathrm{MgSO}_{4}, 11 \mathrm{D}$-glucose and gassed with carbogen $\left(95 \% \mathrm{O}_{2} / 5 \% \mathrm{CO}_{2}\right) ; \mathrm{pH} 7.4 ; 295 \mathrm{mOsm}$. Three hundred fifty - micrometer - thick slices of the hippocampus were prepared and incubated for $1 \mathrm{~h}$ in the same solution at $35.0 \pm 0.5^{\circ} \mathrm{C}$ before recording. Bath solutions were bubbled with carbogen $\left(95 \% \mathrm{O}_{2} / 5 \% \mathrm{CO}_{2}\right)$ and had a $\mathrm{pH} 7.4$.

\section{$\mathrm{Ca}^{2+}$ imaging}

Dye loading. Oregon Green 488 BAPTA-1 AM (OGB-1) $(0.4 \mu \mathrm{M})$ (Invitrogen, USA) dissolved in dimethylsulfoxide with $4 \%$ pluronic acid ( $\mathrm{pH} 7.4$ ) and gassed with $95 \%$ $\mathrm{O}_{2}$ and $5 \% \mathrm{CO}_{2}$ at $35.5^{\circ} \mathrm{C}$. After 40-min incubation for near-full absorption of the OGB-1 molecules by the hippocampal slices. Additionally, the exposed hippocampal slices were also loaded with the astrocytespecific indicator sulforhodamine SR101 $(10 \mu \mathrm{M})$ (Sigma, USA) $[15,16]$. Then slices were transferred to a recording chamber perfused with Ringer solution that contained (in mM) $119 \mathrm{NaCl}, 2.5 \mathrm{KCl}, 1.3 \mathrm{MgSO}_{4}, 1 \mathrm{NaH}_{2} \mathrm{PO}_{4}$, $26.2 \mathrm{NaHCO}_{3}, 2 \mathrm{CaCl}_{2}, 11 \mathrm{D}$-glucose and gassed with carbogen $\left(95 \% \mathrm{O}_{2} / 5 \% \mathrm{CO}_{2}\right) ; \mathrm{pH} 7.4 ; 295 \mathrm{mOsm}$, at a rate of $1-1.5 \mathrm{ml} / \mathrm{min}$. Calcium activity was imaged from the CA3 field of hippocampus.

Optical techniques. A confocal laser-scanning microscope, Zeiss LSM 510 (Germany), with a W PlanApochromat $20 \times / 1.0$ objective used to investigate the spontaneous activity of the neuronal and astrocytic network. Cytosolic $\mathrm{Ca}^{2+}$ was visualized via OGB-1 excitation with the $488 \mathrm{~nm}$ line of Argon laser radiation and emission detection with a 500-530 nm filter, while astrocytes were visualized with SR101, which was excited by $543 \mathrm{~nm}$ radiation from a $\mathrm{He}-\mathrm{Ne}$ laser and detected with the use of a $650-710 \mathrm{~nm}$ filter for emission. Time series of $512 \times 512$-pixel images with a $400 \times 400-\mu \mathrm{m}$ field of view recorded at a rate of $1 \mathrm{~Hz}$. A confocal pinhole of 1 Airy unit ensured an axial optical slice resolution of $1.6 \mu \mathrm{m}[17]$.

Image analysis. Quantitative evaluation of $\mathrm{Ca}^{2+}$ transients was performed off-line using custom-made software in $\mathrm{C}++$ Builder. Cell regions from fluorescent images manually selected. The $\mathrm{Ca}^{2+}$ fluorescence for each cell in each frame calculated as the average fluorescence intensity (relative units from 0 to 255) of the pixels within the defined cell region. Single $\mathrm{Ca}^{2+}$ signals found using the following algorithm. First, averaging two neighboring points in the sample set filtered each trace from all of the cells. Next, we calculated a simple derivative of the signal by calculating a difference between each pair of consequent points. The pulses found from the derivative of the trace using a threshold detection algorithm. The threshold estimated as the detection accuracy coefficient Kdf (Knockdown factor) multiplied by the standard deviation of the derivative of the trace. Suprathreshold points on the derivative of the trace were taken as the beginnings and endings of the pulses. The detection accuracy coefficient Kdf was empirically set to 0.45 .

To detect super-oscillations, we filtered the signal with a low-pass elliptic filter $(0.2 \mathrm{~Hz})$ that removed any regular short calcium pulses. Then, we calculated the derivative of the filtered signal. Each point of the derivative estimated as an average of the differences of the 20 subsequent pairs of points. This definition allowed us to clearly visualize the super-oscillation beginnings and endings. Next, we applied a threshold detection algorithm to detect these super-oscillations. The threshold estimated as the super-oscillation detection accuracy coefficient KSdf (Super-oscillation Knockdown factor) multiplied by the standard deviation of the derivative of the trace. All of the time points that crossed the threshold defined as the beginnings and endings of the super-oscillation. The super-oscillation detection accuracy coefficient KSdf was empirically set to 0.8 .

Pharmacological agents. Tetrodotoxin (TTX) $(1 \mu \mathrm{M})$, L-glutamate $(5 \mu \mathrm{M})$, adenosine 5 'triphosphate (ATP) disodium salt hydrate $(5 \mu \mathrm{M})$ were purchased from SigmaAldrich (USA). The drug solution was prepared immediately before use and perfused into the recording chamber.

Statistical analysis. All data quantification is presented as the mean \pm standard error of the mean (SEM), where $\mathrm{n}$ - the number of cells. Was performed statistical analysis using a Student's t-test in the program Origin 7.0. The experimental data were normally distributed, and then was conducted a two-sided paired Student's t-test for samples with unequal variances. The difference between groups was considered significant if the $p$ value was less than 0.05 .

Cross-correlation analysis. The method for calculation of the cross-correlations used to estimate the degree of synchronization of all pairs of cells. According to this method, two traces removed by the delay time $\tau$. 


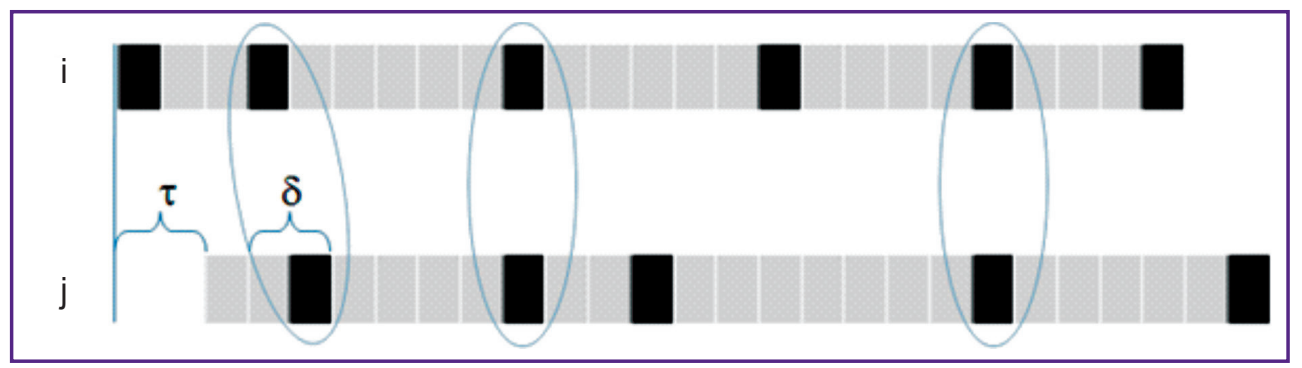

Figure 1. Visualization of the method for cross-correlation calculating for $i$ and $j$ discrete traces of the same duration within the non-zero delay time $\tau$. For this example, $\tau=2 \mathrm{~s}, \delta=1 \mathrm{~s}$. Ratio of pulses calculated by the formula $C_{i j}=n_{\text {synchr }} / \min \left(n_{i} ; n_{j}\right)$ is: $C_{i j}=3 / \min (6 ; 5)=0.6$

Further, the number of synchronous pulses located on both channels in the ranges of tolerance of $2 \delta$ is calculated. In our case $\tau=0 \mathrm{~s}$, and the interval $\delta$ was taken equal to $1 \mathrm{~s}$. Since the active astrocytes oscillation frequency varies in a small, range from cell to cell, the minimum number of pulses in the compared pair of channels used for normalization (Figure 1). Thus, the formula for calculating the cross-correlation matrix looks like:

$$
C_{i j}=n_{\text {synchr }} / \min \left(n_{i} ; n_{j}\right) .
$$

Calculation and visualization of cross-correlation matrices was performed by using standard Matlab algorithms.

\section{Results}

Dynamics of spontaneous $\mathrm{Ca}^{2+}$ oscillations cells in the hippocampal area CA3 in early (P5-8, P14-16) and late (P21-25) postnatal development. Calcium activity of pyramidal neurons, interneurons and astrocytes in the hippocampal area CA3 in early (P5-8, P14-16) and late (P21-25) postnatal development was monitored using functional $\mathrm{Ca}^{2+}$ imaging. In this study, we investigated such parameters of calcium cells activity as a number of $\mathrm{Ca}^{2+}$ oscillations per minute and duration of $\mathrm{Ca}^{2+}$ oscillations. We have demonstrated that spontaneous $\mathrm{Ca}^{2+}$ activity varied depending on the ages of the rat (Figure 2).

Revealed an increase in the duration and decrease in the number of $\mathrm{Ca}^{2+}$ oscillations of pyramidal neurons and interneurons in the transition from early stage to late postnatal development. Duration of $\mathrm{Ca}^{2+}$ oscillations in astrocytes also increased during postnatal ontogenesis, and frequency change was complex. Thus, when comparing animal's younger age group P5-8 with animals P14-16 there was an increase number of astrocytic $\mathrm{Ca}^{2+}$ oscillations, when compared with a group P21-25 showed a significant decrease to values below the level in animal's younger age groups. It is shown that the number of $\mathrm{Ca}^{2+}$ oscillations and its duration depends on the temperature of the perfusion.

In animals, of older age groups are reduced in amount of $\mathrm{Ca}^{2+}$ oscillations in pyramidal neurons by 75 and $96 \%$, interneurons in 41 and $90 \%$ in the age groups P14-16 and P21-25, respectively, when compared with a group of P5-8. The amount of $\mathrm{Ca}^{2+}$ oscillations in astrocytes increased by $84 \%$ in the group P14-16 and decreased by $54 \%$ in the group P21-25, in comparison with a group of animals of 5-8-day postnatal ontogenesis. In the analysis of another parameter of $\mathrm{Ca}^{2+}$ activity of cells "duration of $\mathrm{Ca}^{2+}$ oscillations", the opposite found agerelated dynamics. Since the duration of $\mathrm{Ca}^{2+}$ oscillations pyramidal neurons and astrocytes significantly increased (47 and $71 \%$, respectively) only in the transition from the early neonatal period of ontogenesis (P5-8, P14-16) to late (P21-25). A duration $\mathrm{Ca}^{2+}$ oscillations in interneurons increased by 12 and $66 \%$ in group P14-16 and P21-25, respectively, in comparing with the group P5-8.

Dynamics of $\mathrm{Ca}^{2+}$ oscillations cells in the hippocampal area CA3 of early (P5-8, P14-16) and late (P21-25) postnatal development at infringement conduction of excitation in the neural network. In order to investigate the role of network factors conduction of excitation by outgrowth of neurons from cell to cell in the formation of spontaneous $\mathrm{Ca}^{2+}$ oscillations in neurons and astrocytes of the CA3 field experiments were carrying out with the blockade of voltage-dependent sodium channel by tetrodotoxin (TTX). In Figure 3 is a histogram showing the change in number of $\mathrm{Ca}^{2+}$ oscillations when added to the perfusion solution of TTX $(1 \mu \mathrm{M})$.

When we added to the perfusion solution TTX $(1 \mu \mathrm{M})$ there was observed reduction in the number of $\mathrm{Ca}^{2+}$ oscillations in pyramidal neurons, astrocytes and interneurons in the hippocampal area CA3 of early (P5-8) postnatal development by the 95, 83 and 38\%, respectively. In the age group P14-16 also observed reduction of the number of $\mathrm{Ca}^{2+}$ oscillations, but at 62 , 69 and $61 \%$ of the pyramidal neurons, interneurons and astrocytes, respectively. In animals, the older age group P21-25, the adding TTX to a perfusion solution not caused significantly changes in $\mathrm{Ca}^{2+}$ activity of the cells. It shown that in the early period of postnatal ontogenesis $\mathrm{Ca}^{2+}$ neuronal activity was completely dependent on the activity of the neural network and dramatically decreased with violations of conduct signal on the network, where neurons connected by electrical synapses. In the study, the structure of neural networks shown that in the early postnatal period there is a strict synchronization of activity of pyramidal neurons and interneurons, due to formation of a stable neural network, subject to excitation by electrical synapses. Astrocytes are not involved in 


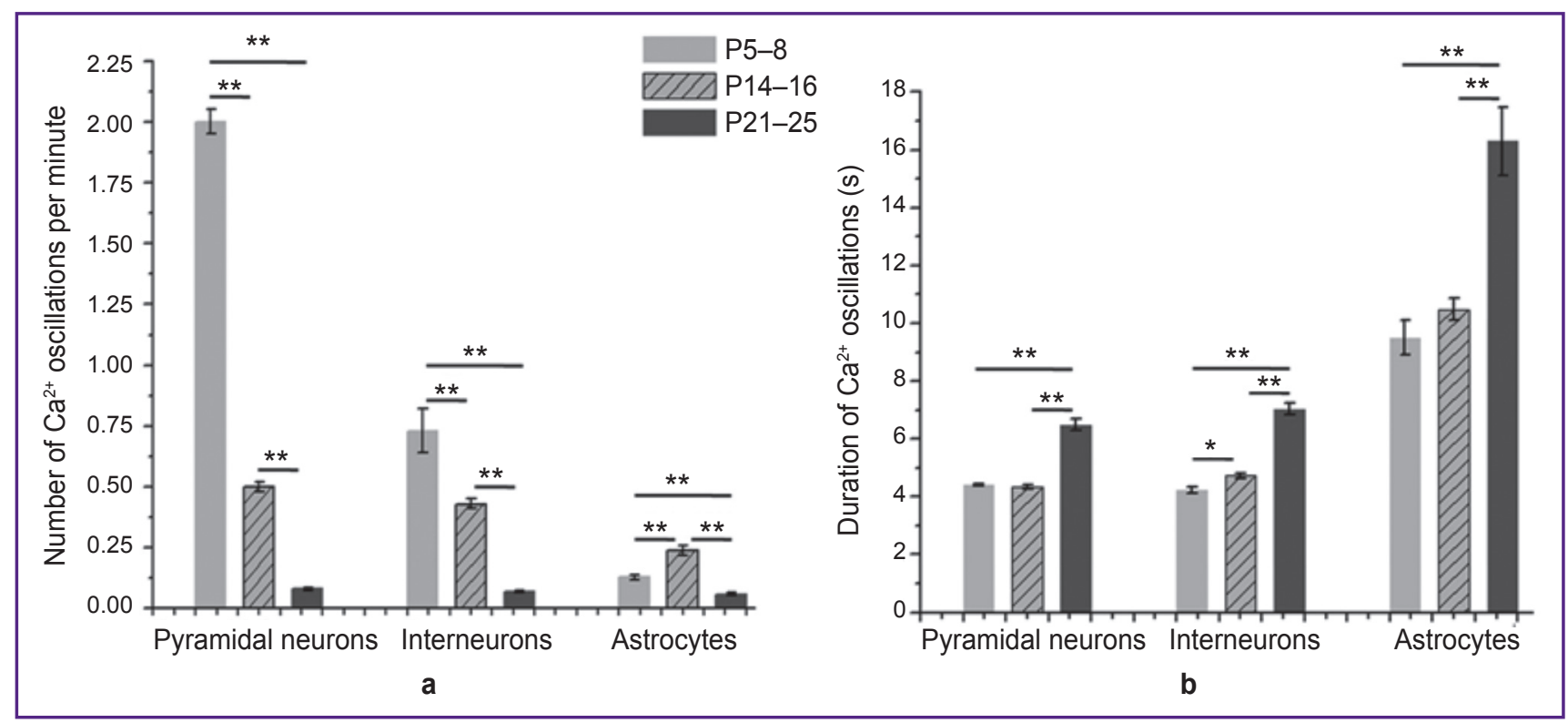

Figure 2. Change (a) the amount of $\mathrm{Ca}^{2+}$ oscillations and (b) the duration in cells of the $\mathrm{CA} 3$ field of rat hippocampus of early (P5-8) and late (P14-16, P21-25) stages of postnatal development. Student's t-test; ${ }^{*} p<0.001,{ }^{* *} p<0.05 ; n=180$

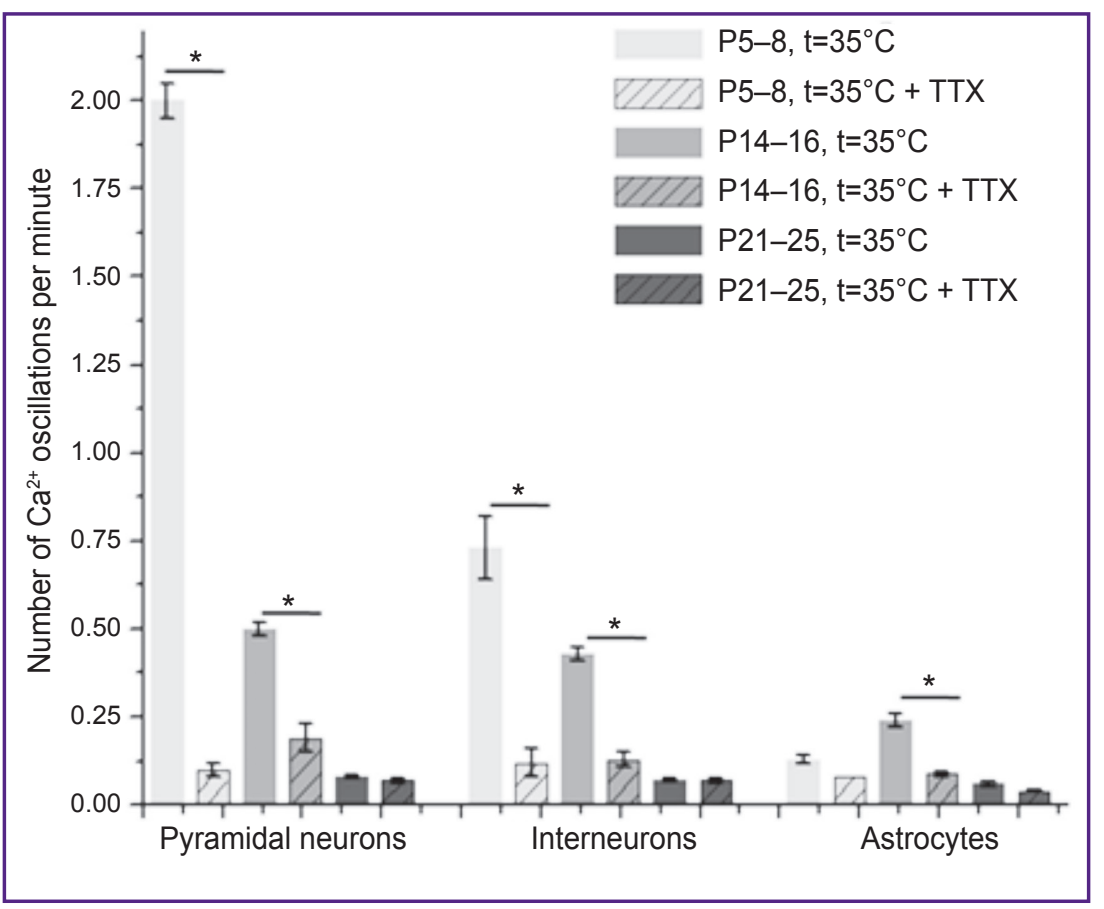

Figure 3. Changing of the amount of $\mathrm{Ca}^{2+}$ oscillations in cells of $\mathrm{CA} 3$ field of rat hippocampus in three age groups (P5-8, $\mathrm{P} 14-16, \mathrm{P} 21-25)$ adding to the perfusion solution of TTX $(1 \mu \mathrm{M})$. Student's t-test; ${ }^{*} \mathrm{p}<0.001 ; n=180$ general functional network at this stage of development (Figure 4).

Spontaneous $\mathrm{Ca}^{2+}$ activity of hippocampal cells of animals of middle age group also depended on network activity, which exists due to partial preservation of electrical synapses at this stage of development, so the addition of TTX also caused reduce the amount of $\mathrm{Ca}^{2+}$ oscillations in neurons. Reduced astrocytic $\mathrm{Ca}^{2+}$ activity in the group $\mathrm{P} 14$ is a response of astrocytes on the activity of neuronal networks, which proved the neuron-glial interactions with 14 days of postnatal development. 14-16 postnatal day the number of working synchronously neurons decreases. Likely, those electrical synapses remained only on pyramidal neurons while on interneurons they were almost absent (Figure 5).

Further studies carrying out on the effect of $t$ TTX on calcium activity of the cells of the hippocampus of rats 21-25 days of ontogenesis. Therefore, absence of effect of TTX on spontaneous $\mathrm{Ca}^{2+}$ cell activity in group 


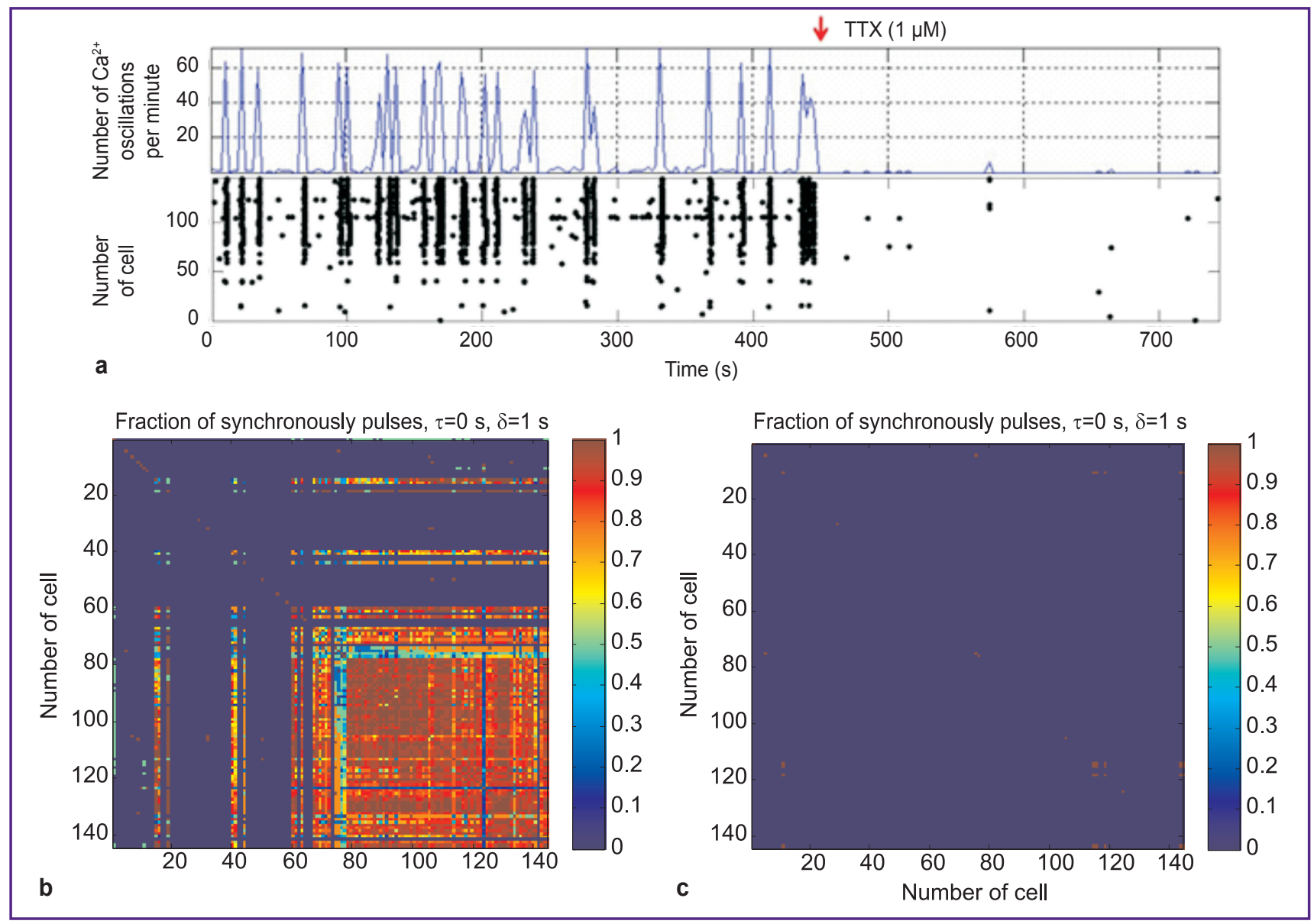

Figure 4. (a) Raster diagram of $\mathrm{Ca}^{2+}$ activity of the cells, the points marked the emergence of $\mathrm{Ca}^{2+}$ oscillations, and a graph of the amount of $\mathrm{Ca}^{2+}$ oscillations in $3 \mathrm{~s}$ from time to time; (b) a cross-correlation matrix, which allows to evaluate the synchronicity of $\mathrm{Ca}^{2+}$ oscillations occurrence of cell of field CA3 of rat hippocampus of early (P5-8) postnatal development; (c) a cross-correlation matrix, which allows to evaluate the synchronicity of $\mathrm{Ca}^{2+}$ oscillations occurrence of cell of CA3 field of rat hippocampus of early (P5-8) postnatal development when added to the perfusion solution of TTX $(1 \mu \mathrm{M})$

P21-25, due to the lack of spontaneous activity in the neural network CA3 field of hippocampal slices, in which neurons are connected by chemical synapses. We did not observe changes in $\mathrm{Ca}^{2+}$ activity of astrocytes accordingly (Figure 6).

At the age of $21-25$ days of postnatal period is observed fully formed neural network with significant predominance of chemical synapses, the presence of a molecular network of the extracellular matrix of the brain active metabolic system synthesis and degradation of neurotransmitters, neuromodulators, a set of proteins of the transport system, both on the outer cell membrane and internal organelles.

For studying mechanisms of spontaneous $\mathrm{Ca}^{2+}$ oscillations in neurons and astrocytes of mature network, we have carried out experiments with the addition of excitatory neurotransmitters - L-glutamate and ATP.

Dynamics of $\mathrm{Ca}^{2+}$ oscillations cells in the CA3 field of hippocampus of late (P21-25) postnatal development under the influence of excitatory neurotransmitters (ATP, L-glutamate). L-glutamate and ATP control about $80 \%$ of synaptic transmission in the hippocampus. Addition of TTX in the perfusion solution allows evaluating the work of individual synapses and cells. Figure 7 shows the relative change in the number of $\mathrm{Ca}^{2+}$ oscillations in the cells of CA3 field of rat hippocampus P21-25 under the influence of ATP $(20 \mu \mathrm{M})$ and L-glutamate $(20 \mu \mathrm{M})$.

It has been shown that when in the perfusion solution added ATP - agonist of P2 receptors there is an increase of numbers of $\mathrm{Ca}^{2+}$ oscillations in cells of CA3 field of rats hippocampus: on pyramidal neurons at 100 , $85 \%$ on interneurons and in 2 times in astrocytes. After addition into perfusion solution of L-glutamate - agonist of glutamate receptors there was registered an increase in the number of $\mathrm{Ca}^{2+}$ oscillations in cells of CA3 field of rat hippocampus: by $71 \%$ in pyramidal neurons, $42 \%$ in interneurons and $100 \%$ in astrocytes.

The next stage of our work was to study the network activity of rat hippocampal cells of the late postnatal 


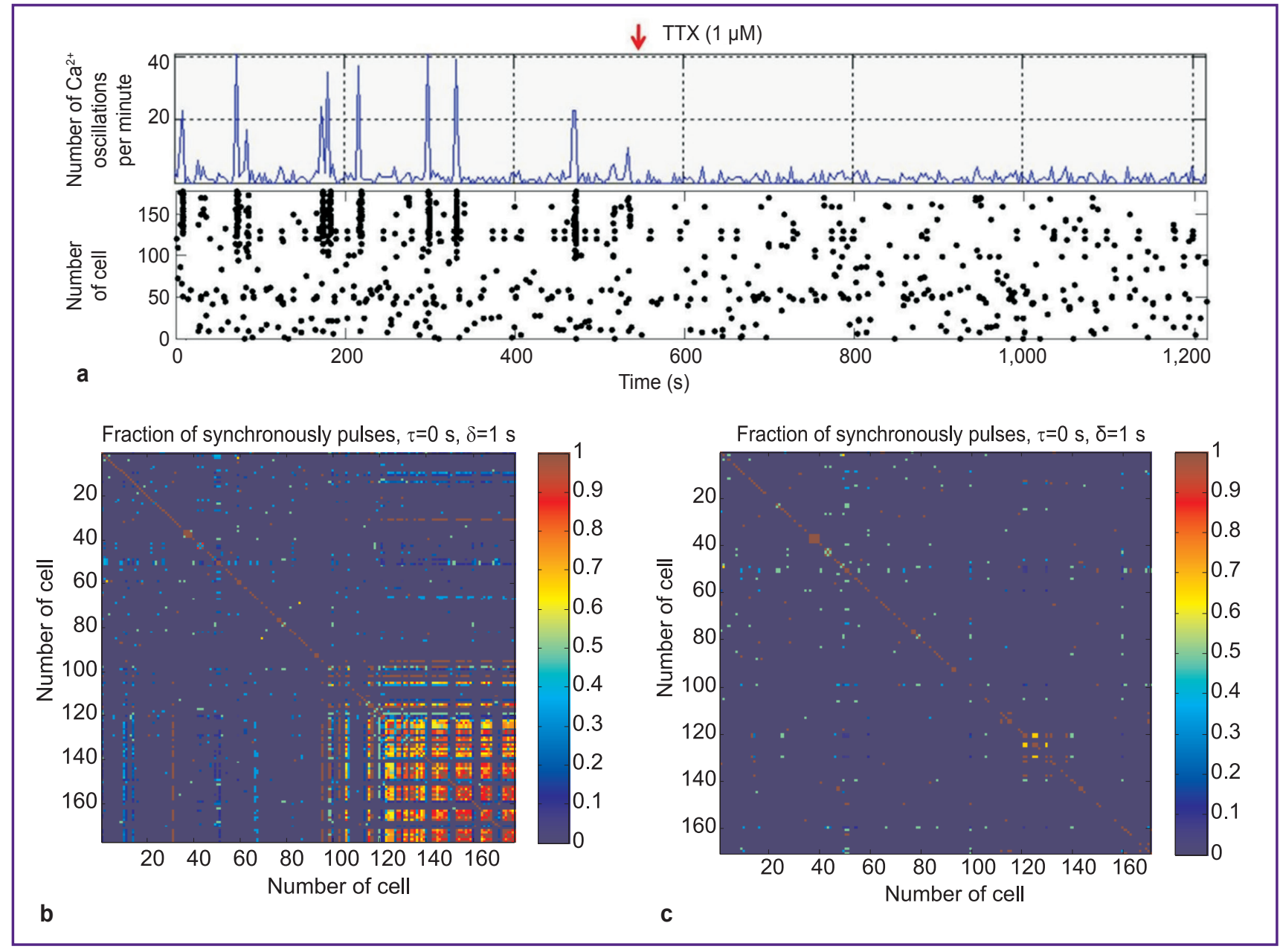

Figure 5. (a) Raster diagram $\mathrm{Ca}^{2+}$ activity of the cells, the points marked the emergence of $\mathrm{Ca}^{2+}$ oscillations, and a graph of the amount of $\mathrm{Ca}^{2+}$ oscillations in $3 \mathrm{~s}$ from time to time; (b) a cross-correlation matrix, which allows to evaluate the synchronicity of $\mathrm{Ca}^{2+}$ oscillations occurrence of cell of CA3 field of rat hippocampus of early (P14-16) postnatal development; (c) a cross-correlation matrix, which allows to evaluate the synchronicity of $\mathrm{Ca}^{2+}$ oscillations occurrence of cell field CA3 of rat hippocampus of early (P14-16) postnatal development when added to the perfusion solution of TTX (1 $\mu \mathrm{M})$

development in network activation of excitatory neurotransmitters. Thus, it was shown that at preservation excitation of the neural network, ATP and L-glutamate dependent activation of synaptic transmission resulted in a significant increase in $\mathrm{Ca}^{2+}$ activity in the network as reflected in the presence of synchronizing between the cells by adding excitatory neurotransmitters, as demonstrated by the cross-correlation matrixes (Figures 8, 9).

While maintaining the excitation of a neural network, ATP and L-glutamate-dependent activation of synaptic transmission resulted in a significant increase in $\mathrm{Ca}^{2+}$ activity in the network. This reflected in the presence of synchronization between cells when added excitatory neurotransmitters (See Figures 8, 9).

Discussion. Reducing the amount of $\mathrm{Ca}^{2+}$ oscillations during the transition from early stage to the late neonatal period due to the formation and complication synaptically connected neural networks and the transition of electrical synapses into the chemical. Transitional period is 14-16 days of postnatal ontogenesis, when on cells begin to dominate chemical synapses, to 21 days - there is a fully formed neural network. In the absence of afferentation in a slice, the network is silent, so the external manifestations of network activity, expressed in $\mathrm{Ca}^{2+}$ activity of the cells is very low.

Furthermore, when considering the characteristics of the age-dependent $\mathrm{Ca}^{2+}$ signaling should be noted that during embryogenesis rats presented only kainate and metabotropic glutamate receptors, other types of receptors appear only on days 5-7 of postnatal development. A highest involvement of glutamate and ATP-activated receptor $\mathrm{Ca}^{2+}$ signaling is observed on days 20-25 of postnatal development [18-23]. Excitation is freely distributed in the chemical network, involving all cells in the work, which is manifested in high $\mathrm{Ca}^{2+}$ activity 


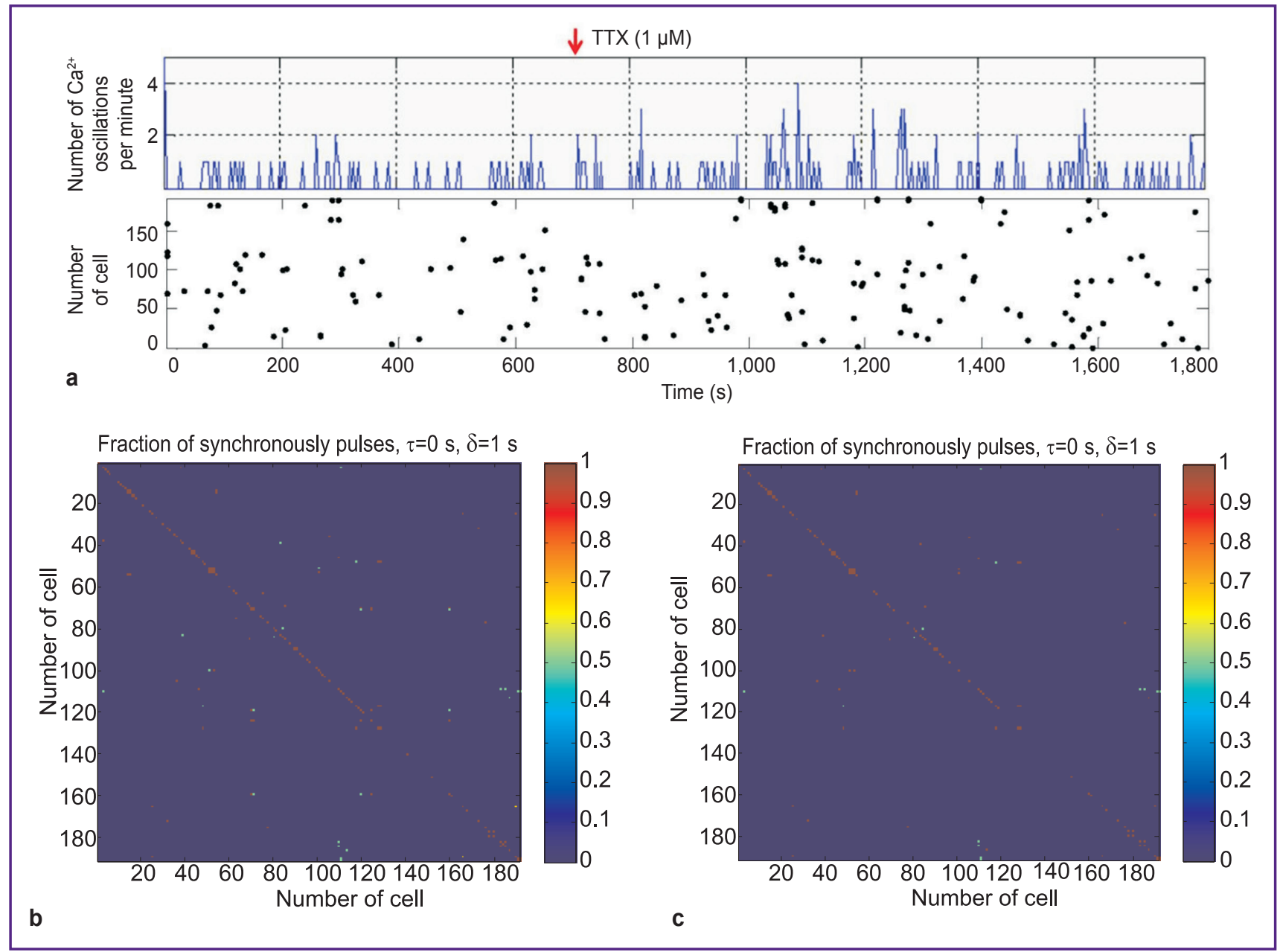

Figure 6. (a) Raster diagram of $\mathrm{Ca}^{2+}$ activity of the cells, the points marked the emergence of $\mathrm{Ca}^{2+}$ oscillations, and a graph of the amount of $\mathrm{Ca}^{2+}$ oscillations in $3 \mathrm{~s}$ from time to time; (b) a cross-correlation matrix, which allows to evaluate the synchronicity of $\mathrm{Ca}^{2+}$ oscillations occurrence of cell of CA3 field of rat hippocampus of the late (P21-25) postnatal development; (c) a cross-correlation matrix, which allows to evaluate the synchronicity of $\mathrm{Ca}^{2+}$ oscillations occurrence of cell of $\mathrm{CA} 3$ field of rat hippocampus of the late (P21-25) postnatal development when added to the perfusion solution of TTX (1 $\mu \mathrm{M})$

Figure 7. The relative change amounts of $\mathrm{Ca}^{2+}$ oscillations in the cells of CA3 field of rat hippocampus P21-25 when exposed by ATP $(20 \mu \mathrm{M})$ and L-glutamate $(20 \mu \mathrm{M})$. Dashed line: control values $\mathrm{Ca}^{2+}$ activity in registration with the addition to the perfusion solution of TTX $(1 \mu \mathrm{M})$. Student's t-test; $\mathrm{p}<0.001 ; \mathrm{n}=150$

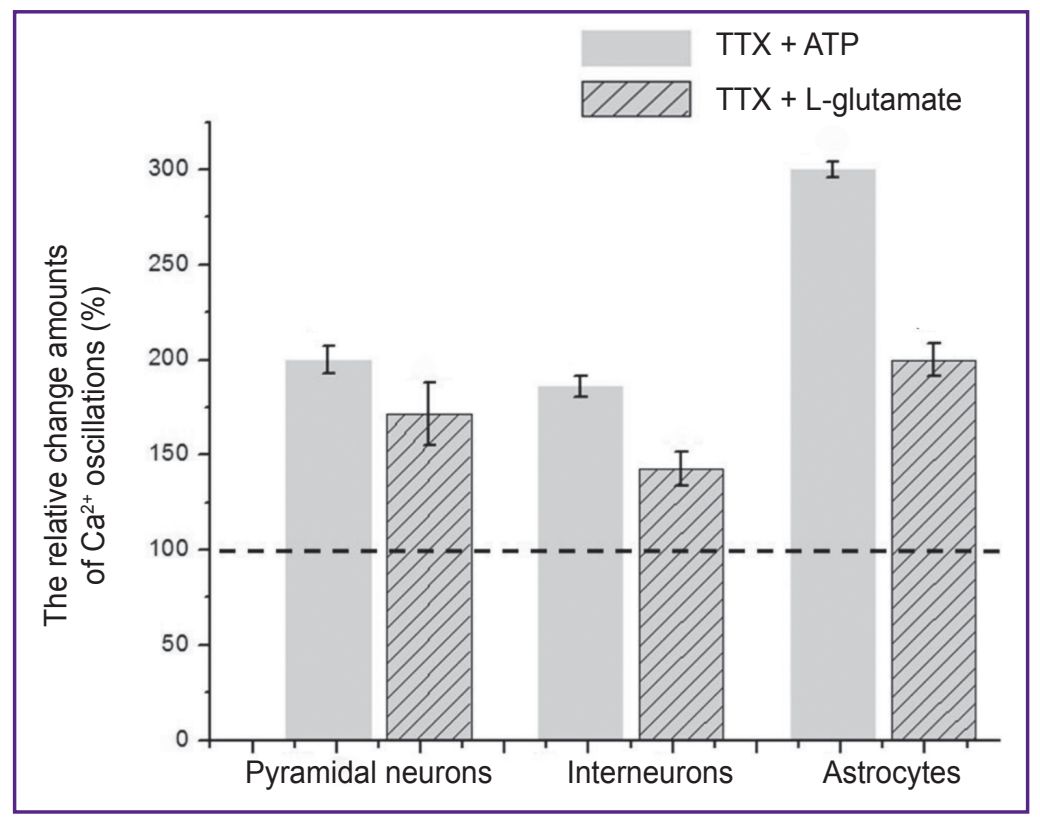




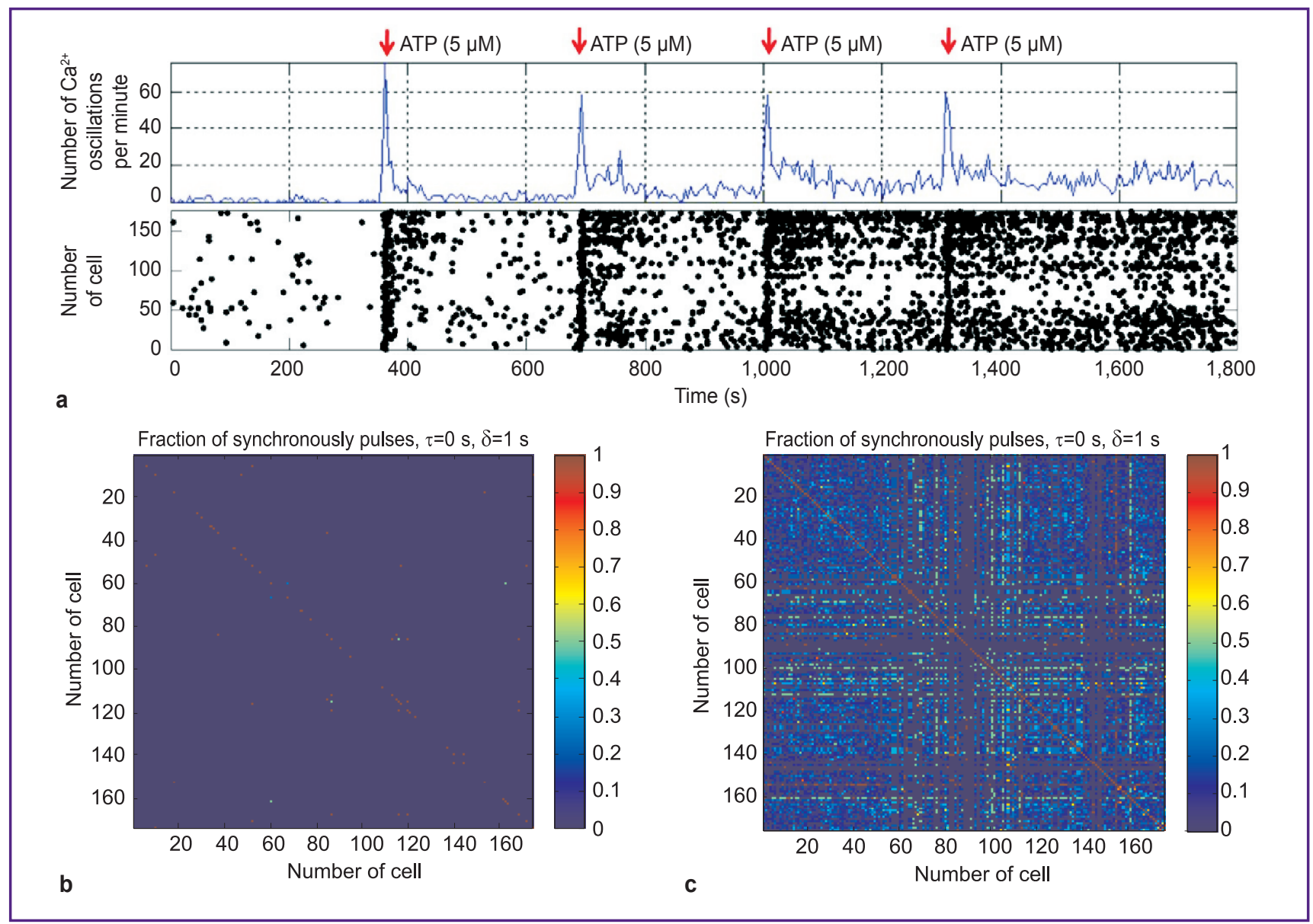

Figure 8. (a) Raster diagram $\mathrm{Ca}^{2+}$ activity of the cells, the points marked the emergence of $\mathrm{Ca}^{2+}$ oscillations, and a graph of the amount of $\mathrm{Ca}^{2+}$ oscillations in $5 \mathrm{~s}$ from time to time; (b) a cross-correlation matrix, which allows to evaluate the synchronicity of $\mathrm{Ca}^{2+}$ oscillations occurrence of cell of CA3 field of rat hippocampus of the late (P21-25) postnatal development; (c) a cross-correlation matrix, which allows to evaluate the synchronicity of $\mathrm{Ca}^{2+}$ oscillations occurrence of cell of CA3 field of rat hippocampus of the late (P21-25) postnatal development when added to the perfusion solution of ATP (5 $\mu$ M)

of the cells of rat hippocampus of the early postnatal ontogenesis.

In addition, the high activity of the cells of rat hippocampus of the early postnatal development may be associated with the depolarizing effect of GABA at this stage of ontogenesis. A group of scientists led by Ben-Ari et al. in 1989 [24] in the study of ontogenesis of pyramidal neurons CA3 field of rat hippocampal slices, shown that the transition to hyperpolarizing action of GABA takes place on days 5-6 of postnatal development of the animal. Networking events associated with GABA-mediated GDP disappeared in day 12 of rat postnatal development. Recent studies have shown that the transition from the exciting action to the inhibitory GABAergic potentials occurs about 14 days of postnatal development.

Important to note that in the process of development the GDP appearance coincides with the formation of ionotropic glutamatergic transmission in the pyramidal neurons of CA3 fields of the hippocampus [24, 25]. It is shown that ionotropic glutamatergic transmission, mediated mainly by work of AMPA receptors is crucial for the generation of GDP. Thus, during postnatal development of the hippocampus are several steps affecting formation of cell networks.

In order to prove the role of neural networks in the formation of spontaneous $\mathrm{Ca}^{2+}$ oscillations in the cells of the CA3 field of hippocampal slices of different age groups, we performed experiments with the blockade of excitation in the neural networks with the help of a blocker of voltage-dependent sodium channel TTX $(1 \mu \mathrm{M})$. We have shown that in the early neonatal period, of postnatal ontogenesis $\mathrm{Ca}^{2+}$ activity of the neurons was completely dependent on the activity of neural networks and abruptly decreased with violations of the signal of a neural network in which the neurons connected by electrical synapses. Spontaneous $\mathrm{Ca}^{2+}$ activity of the cells of the hippocampus of animals the middle age group (P14-16) also dependent on network activity, the current due to partial preservation of electrical synapses 


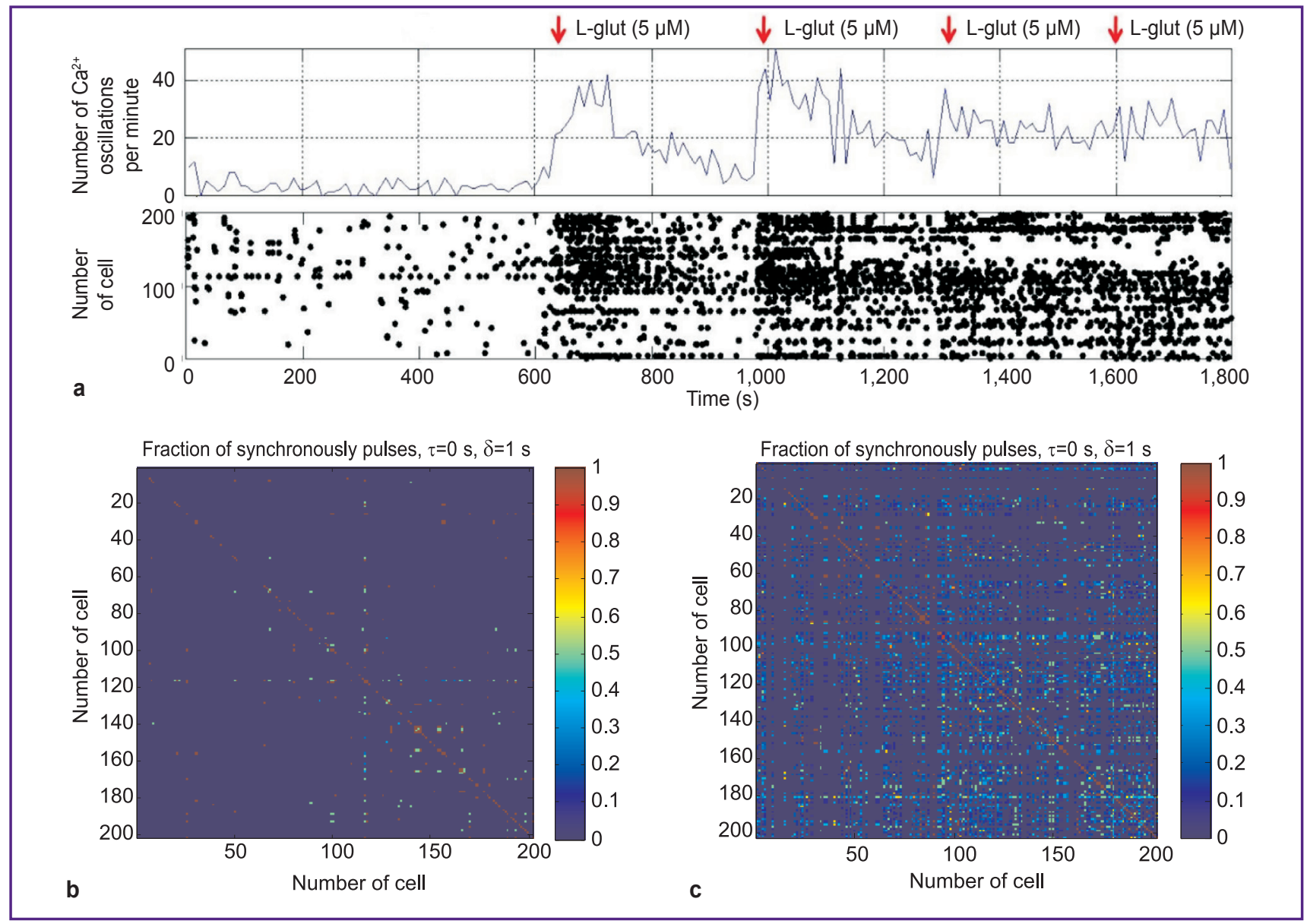

Figure 9. (a) Raster diagram $\mathrm{Ca}^{2+}$ activity of the cells, the points marked the emergence of $\mathrm{Ca}^{2+}$ oscillations, and a graph of the amount of $\mathrm{Ca}^{2+}$ oscillations in $5 \mathrm{~s}$ from time to time; (b) a cross-correlation matrix, which allows to evaluate the synchronicity of $\mathrm{Ca}^{2+}$ oscillations occurrence of cell of CA3 field of rat hippocampus of the late (P21-25) postnatal development; (c) a cross-correlation matrix, which allows to evaluate the synchronicity of $\mathrm{Ca}^{2+}$ oscillations occurrence of cell of CA3 field of rat hippocampus of the late (P21-25) postnatal development when added to the perfusion solution of L-glutamate (5 $\mu \mathrm{M})$

at this stage of development, so the addition of TTX also reduces the amount of $\mathrm{Ca}^{2+}$ oscillations in neurons. Decrease of astrocytic $\mathrm{Ca}^{2+}$ activity in the group P14-16 is a response of astrocytes on the activity of neuronal networks that proves the presence of neuron-glia interactions with 14 days of postnatal development. Lack of effect of TTX on spontaneous $\mathrm{Ca}^{2+}$ activity of the cells of P21-25, due to the lack of spontaneous activity of the neural network in the CA3 field of hippocampal slices in which neurons connected by chemical synapses. Consequently, we did not observe changes in astrocytic $\mathrm{Ca}^{2+}$ activity. Also has been studied the structure of neural networks, whereby it was shown that in the early neonatal period of postnatal ontogenesis there is a strict synchronization of activity of pyramidal neurons and interneurons by forming a stable neural network subject to excitation through electrical synapses. Astrocytes at this stage of development of common functional network are not involved. In a mature network, violation of excitation of axons almost had no effect on $\mathrm{Ca}^{2+}$ activity of the cells, as a spontaneous network activity in a slice missing.

Further research has focused on the $\mathrm{Ca}^{2+}$ activity of the cells of the CA3 field of hippocampal slices of rats late (P21-25) neonatal period of postnatal ontogenesis. To study the mechanism of spontaneous $\mathrm{Ca}^{2+}$ oscillations in neurons and astrocytes mature network experiments carried out with the addition of excitatory neurotransmitters - ATP and L-glutamate. In rest in the animal hippocampus extracellular glutamate levels ranging from 1 to $2 \mu \mathrm{M}$, and the ATP level of $100 \mathrm{nM}$. A concentration of these substances in $20 \mu \mathrm{M}$ considered half maximal effective concentration, and can be observed with increased activity of the brain, for example during a research of animal behavior. This study allowed us to estimate the dependence of $\mathrm{Ca}^{2+}$ activity in the of cell of CA3 field of rat hippocampus of the late (P21-25) postnatal period from metabolic state of cells associated with increased release of neurotransmitters into the synaptic cleft. Furthermore, 
it was shown that under the conditions of a mature network when spontaneous $\mathrm{Ca}^{2+}$ cell activity is low while maintaining the conduction of excitation by adding the neural network of excitatory neurotransmitters cause strict synchronization of cell activity. In the papers [4, $10,11,13]$ aimed at studying the neural networks in the hippocampus was also shown that about $60 \%$ of the neurons responded to sensory irritation, due to feature in the structure of the hippocampus.

The study showed that changes in $\mathrm{Ca}^{2+}$ activity in the cells CA3 field of rat hippocampal taking place during the neonatal period of postnatal ontogenesis directly related to the functioning of neural networks and the metabolic state of the cells. $\mathrm{Ca}^{2+}$ signaling in the developing brain is a complex multi-component process involving various receptor systems capable of mutual substitution in case of violation the normal functioning of one or more of them.

Study of $\mathrm{Ca}^{2+}$ signaling brain cells refers to a number of key problems of fundamental neuroscience, as the processes of cell signaling and neuron-glial interactions play a decisive role in the functioning of the nervous system.

Acknowledgments. The research was supported by the Federal Target Program "Research and development in priority areas of the development of the scientific and technological complex of Russia for 2014-2020" of the Ministry of Education and Science of Russia (Project ID RFMEFI60715X0117).

Conflicts of Interest. The authors have no conflicts of interest to disclose.

\section{References}

1. Nedergaard M., Rodríguez J.J., Verkhratsky A. Glial calcium and diseases of the nervous system. Cell Calcium 2010; 47(2): 140-149, https://doi.org/10.1016/j. ceca.2009.11.010.

2. Petersen O.H., Michalak M., Verkhratsky A. Calcium signalling: past, present and future. Cell Calcium 2005; 38(34): 161-169, https://doi.org/10.1016/j.ceca.2005.06.023.

3. Nett W.J., Oloff S.H., McCarthy K.D. Hippocampal astrocytes in situ exhibit calcium oscillations that occur independent of neuronal activity. J Neurophysiol 2002; 87(1): 528-537.

4. Takahashi N., Sasaki T., Usami A., Matsuki N., Ikegaya Y. Watching neuronal circuit dynamics through functional multineuron calcium imaging (fMCl). Neurosci Res 2007; 58(3): 219-225, https://doi.org/10.1016/j. neures.2007.03.001.

5. Verkhratsky A., Rodríguez J.J., Parpura V. Calcium signalling in astroglia. Mol Cell Endocrinol 2012; 353(1-2): 4556, https://doi.org/10.1016/j.mce.2011.08.039.

6. Clapham D.E. Calcium signaling. Cell 2007; 131(6): 1047-1058, https://doi.org/10.1016/j.cell.2007.11.028.

7. Parpura V., Verkhratsky A. Astrogliopathology: could nanotechnology restore aberrant calcium signalling and pathological astroglial remodelling? Biochim Biophys Acta 2013; 1833(7): 1625-1631, https://doi.org/10.1016/j. bbamcr.2012.11.023.
8. Rose C.R., Konnerth A. Stores not just for storage. Neuron 2001; 31(4): 519-522, https://doi.org/10.1016/s08966273(01)00402-0.

9. Collin T., Marty A., Llano I. Presynaptic calcium stores and synaptic transmission. Curr Opin Neurobiol 2005; 15(3): 275-281, https://doi.org/10.1016/j.conb.2005.05.003.

10. Mazzoni A., Broccard F.D., Garcia-Perez E., Bonifazi P., Ruaro M.E., Torre V. On the dynamics of the spontaneous activity in neuronal networks. PLoS One 2007; 2(5): e439, https://doi.org/10.1371/journal.pone.0000439.

11. Li X., Ouyang G., Usami A., Ikegaya Y., Sik A. Scale-free topology of the CA3 hippocampal network: a novel method to analyze functional neuronal assemblies. Biophys J 2010; 98(9): 1733-1741, https://doi.org/10.1016/j. bpj.2010.01.013.

12. Shi Y., Ikrar T., Olivas N.D., Xu X. Bidirectional global spontaneous network activity precedes the canonical unidirectional circuit organization in the developing hippocampus. J Comp Neurol 2014; 522(9): 2191-2208, https://doi.org/10.1002/cne.23528.

13. Tsukamoto-Yasui M., Sasaki T., Matsumoto W., Hasegawa A., Toyoda T., Usami A., Kubota Y., Ochiai T., Hori T., Matsuki N., Ikegaya Y. Active hippocampal networks undergo spontaneous synaptic modification. PLoS One 2007; 2(11): e1250, https://doi.org/10.1371/journal.pone. 0001250.

14. Sipilä S. Cellular and network mechanisms generating spontaneous population events in the immature rat hippocampus. Academic Dissertation. Helsinki; 2006.

15. Paredes R.M., Etzler J.C., Watts L.T., Zheng W., Lechleiter J.D. Chemical calcium indicators. Methods 2008; 46(3): 143-151, https://doi.org/10.1016/j.ymeth.2008. 09.025 .

16. Kang J., Kang N., Yu Y., Zhang J., Petersen N., Tian G-F. N.M. Sulforhodamine 101 induces long-tem potentiation of intrinsic excitability and synaptic efficacy in hippocampal CA1 pyramidal neurons. Neuroscience 2011; 169(4): 1601-1609, https://doi.org/10.1016/j. neuroscience.2010.06.020.

17. Zakharov Yu.N., Mitroshina E.V., Vedunova M.V., Korotchenko S.A., Kalintseva Ya.I., Mukhina I.V., Potanina A.V. Fluorescence analysis of the metabolic activity patterns of neuronal-glial network. Journal of Optical Technology 2012; 79(6): 47-51, https://doi.org/10.1364/jot.79.000348.

18. Bernstein M., Behnisch T., Balschun D., Reymann K.G., Reiser G. Pharmacological characterisation of metabotropic glutamatergic and purinergic receptors linked to $\mathrm{Ca}^{2+}$ signalling in hippocampal astrocytes. Neuropharmacology 1998; 37(2): 169-178, https://doi. org/10.1016/S0028-3908(98)00012-4.

19. Zur Nieden R., Deitmer J.W. The role of metabotropic glutamate receptors for the generation of calcium oscillations in rat hippocampal astrocytes in situ. Cereb Cortex 2006; 16(5): 676-687, https://doi.org/10.1093/cercor/bhj013.

20. Zhong J., Carrozza D.P., Williams K., Pritchett D.B., Molinoff P.B. Expression of mRNAs encoding subunits of the NMDA receptor in developing rat brain. J Neurochem 1995; 64(2): 531-539, https://doi.org/10.1046/j.1471-4159.1995. 64020531.x.

21. Zhou M., Kimelberg H.K. Freshly isolated hippocampal CA1 astrocytes comprise two populations differing in glutamate transporter and AMPA receptor expression. J Neurosci 2001; 21(20): 7901-7908. 
22. Hunter R.G., Bellani R., Bloss E., Costa A., McCarthy K., McEwen B.S. Regulation of kainate receptor subunit mRNA by stress and corticosteroids in the rat hippocampus. PLoS One 2009; 4(1): e4328, https://doi. org/10.1371/journal.pone.0004328.

23. Butt A.M. ATP: a ubiquitous gliotransmitter integrating neuron-glial networks. Semin Cell Dev Biol 2011; 22(2): 205213, https://doi.org/10.1016/j.semcdb.2011.02.023.
24. Ben-Ari Y., Cherubini E., Corradetti R., Gaiarsa J.-L. Giant synaptic potentials in immature rat CA3 hippocampal neurones. J Physiol 1989; 416(1): 303-325, https://doi. org/10.1113/jphysiol.1989.sp017762.

25. Khazipov R., Esclapez M., Caillard O., Bernard C., Khalilov I., Tyzio R., Hirsch J., Dzhala V., Berger B., Ben-Ari Y. Early development of neuronal activity in the primate hippocampus in utero. J Neurosci 2001; 21(24): 9770-9781. 